\title{
LA PRÁCTICA EN LA PEDAGOGÍA UN ENFOQUE DINÁMICO
}

\section{Judith De Palacio.*}

Entender la práctica como la aplicación de leyes y principios de una ciencia o técnica, o como el espacio para adquirir experiencia a través de la repetición de actos y costumbres, o como el cumplimiento de un deber de toda persona que se prepara para ejercer una profesión u oficio, o como el hacer lo mismo muchas veces, no amerita discusión alguna, según piensan algunos.

Sin embargo, abordar el término "práctica" en el campo de lo pedagógico, ha de remitirnos a la discusión o por lo menos a la reflexión, y más, cuando el tema se presenta en el seno de una institución denominada "Universidad Pedagógica Nacional", y específicamente en una de sus dependencias académicas, el Departamento de Educación Física.

Comúnmente en los centros de formación de maestros la práctica ha sido concebida como la aplicación de un conjunto de formas preestablecidas de transmisión de un saber. Dicho en términos cotidianos, es lo que se conoce como el aprender a enseñar, y en términos académicos la adquisición de habilidades docentes y/o didácticas orientadas. controladas y supervisadas por un maestro ya titulado de la institución en la cual se forma al futuro maestro o profesional de la educación.

La práctica desde esta visión tiene como objetivo la instrumentalización de la transmisión en búsqueda de la eficiencia del desempeño del maestro. Esta postura frente a la práctica en el campo de lo pedagógico se encuentra vigente, dando lugar a que el maestro se constituya en un oficiante, o mejor, en un operario dentro de la empresa de producción, perdón, de repetición informativa.

Se entiende que no existen concepciones unívocas, estáticas sobre nada. La concepción de práctica en el campo de lo pedagógico puede verse de otras maneras. Las prácticas en el campo de lo pedagógico se han sustentado en todas las épocas y momentos históricos en la utopía de un proyecto de desarrollo humano que responda a las condiciones culturalmente creadas, influenciadas éstas por factores sociales, económicos y políticos. Significa esto que las prácticas pedagógicas son cambiantes, porque cambiante es el proyecto de desarrollo humano ideado en cada sociedad, o impuesto por una sociedad a otra, sin que medie ningún tamiz en la adaptación del proyecto dentro de la sociedad a la cual se le impone.

La educación entendida como "formas" de transmisión de la cultura, opta por modelos pedagógicos que orientan las prácticas pedagógicas. Son las prácticas pedagógicas los espacios de operacionalización de los modelos pedagógicos a través dc los cuales se internaliza, sistematiza y norman las formas de transmisión de la cultura de una sociedad, para que se ejecute el proyecto de desarrollo humano ideado o impuesto.

La institucionalización de un manejo y aplicación carentes de crítica de las formas de transmisión de la cultura, ha favorecido el desconocimiento social del saber pedagógico del maestro y ha llevado a convertir la profesión de educador en el simple hecho de "dictar

\footnotetext{
* Profesora del Opto de EF. UPN. 
clases". Porque tal cosa no exige más que un saber específico para ser transmitido a otros, independientemente del análisis contextual y del proyecto de desarrollo humano que subyace en las formas instrumentalizadas de transmisión al "dictar clases".

Las prácticas en el campo de lo pedagógico han de ser un espacio de reflexión sobre el acto educativo ya que es la pedagogía la que lo intencionaliza y sistematiza. Una práctica en el campo de lo pedagógico no ha de tener exclusivamente como objetivo el manejo instrumental de la transmisión del saber aprendido. También ha de habilitar al futuro maestro en una formación metodológica para analizar y cuestionar sobre la construcción del conocimiento científico y del saber que transmite, sobre el cómo, por qué, desde dónde y hacia dónde se dan y dirigen los procedimientos del enseñar y aprender para no perder de vista que detrás de las formas de transmisión hay proyectos de desarrollo humano diferentes.

La tarea es preparar docentes en esta metodología (investigativa) de rescatar el saber pedagógico, como saber elaborado y operacionalizado por los maestros como agentes participantes en el proceso pedagógico. El rescate del saber pedagógico es otra posibilidad de concebir la práctica en el campo de lo pedagógico. Un saber pedagógico entendido como la reflexión sobre el acto educativo ha de concretarse en la creación de formas de concebir y de operacionalizar la enseñanza, donde la instrumentalización de la transmisión sea una consecuencia de la reflexión y no la finalidad de la formación del maestro.

La reflexión sobre el acto educativo exige del maestro la revisión permanente de los fundamentos de la disciplina que enseña, el disentimiento argumentado, la divergencia de pensamiento, la posición de la alteridad en tomo a la formación que se recibe como supuestos fundantes del acto educativo a partir del descubrimiento de las relaciones histórico-sociales, culturales y ambientales.

Es comprensible desde esta óptica de la práctica en el campo de lo pedagógico, el por qué en otras instituciones de formación profesional, se descarta el análisis de la disciplina que se enseña desde el saber pedagógico, pues no es conveniente cuestionar las condiciones en que opera la construcción ideologizante que ostentan, porque esto implicaría la ruptura de las relaciones de poder a través del aprendizaje. Las prácticas en el campo de lo pedagógico con visión exclusivamente instrumental son ocultadoras, conscientes o inconscientes, de un proyecto de desarrollo humano implícito pero que a largo plazo la crítica se encargará de evidenciar. 